\title{
Systematic and robust air cleanser for cleaning a pollution caused by the Rocket Stove
}

\author{
Aashish Umakant Gandigude, Madhva V. Nagarhallib \\ Savitribai Phule, Pune University, Pune, India
}

\begin{abstract}
Cooking has become a challenge in areas where the energy access is limited and the single available fuel is wood. Day by day, more people have been reported with respiratory diseases, caused mainly by the smoke that emits carbon monoxide (CO), particular matters (PM) and other highly harmful compounds resulting from the poor combustion generated on the simplest stoves those using fuel wood. Hence an efficient, hot burning Rocket Stove has been deployed with fabric filters in the earlier days. However, the rocket stoves with fabric filter removes the PM content that is also in small amount mean while considering $\mathrm{CO}, \mathrm{CO} 2$ and other toxics remains same in the emitted gas/smoke. To tackle with these pollution issues, our proposed work innovates a Bi-folded Colander Framework, which combines a Knapsack filter and simulated Carbon with Cellulose Nano fiber filter to purify the exhaust gas/smoke. It is highly sensitive to filter the nano particles as well the toxic compounds exist in the exhaust smoke. Thus our proposed methodology effectively reduces the pollutions with our novel framework and enhances the fuel efficiency of the rocket stove.
\end{abstract}

Keywords: Particular matters (PM), Carbon monoxide (CO), Carbon dioxide, Bi-folded Colander Framework, Knapsack filter, simulated Carbon with Cellulose Nano fiber filter.

\section{INTRODUCTION}

People living in areas where the resources are not easily available and the energy access is limited, cooking could be a challenge. In many developing countries the most commonly used fuel is wood. The rigorous use of firewood for cooking has highly contributed to increased carbon emissions and deforestation in developing countries. So that recent technologies develops various energy efficient stoves. One of the technologies is the Rocket stove, which burns at higher temperature than the standard wood-stove or fireplace and, as a result, it emits much cleaner exhaust. In a rocket stove, straw, dried dung, small bundles of twigs etc., has been used to burn [1]. This flexibility and the combined brutal efficiency of these stove has made them a popular choice in this developing world. Conversely, the conventional stoves are too smoky and are inefficient, so that they are replaced with other modern technological stoves (i.e. fabric filter stoves etc.).Smoky kitchens initiate negative impacts on the health of millions of people [2].

The wood fuel is commonly used throughout the world depending on their energy requirements and the supply situation. Extended exposure to biomass emission significantly increases the risk of acute respiratory infections, chronic bronchitis, and obstructive pulmonary disease [3]. The same situation applies to the use of cook stoves in developing countries. Improved cook stoves typically fall into three categories: gasifier stoves, rocket stoves, and forced-air stoves. It suggests, further mechanical design changes to prevent the $\mathrm{PM}$ as well as $\mathrm{CO}$ emission. In addition, similar to mechanical design changes chemical changes are employed with the introduction of oxidation catalyst [4].

Recent improvements in stove design have resulted in a potential reduction in air pollution by improved control over the supply of air in the primary and secondary combustion chambers. However, increased particulate and pollution formation will result during cold-starting and reloading of fuel (refueling). Thus lower emissions are dependent on operational practices but also on the fuel properties. The use of pellet stoves and boilers and wood pellets with suitably defined fuel specifications has greatly improved the environmental impact in regions where it is economical to use these processed fuels [5]. However in many cases logs are used and there are inadequacies in fuel properties with regard to size and moisture content (MC). High moisture contents contribute to limited thermal performance and enhanced pollutant emissions following slow or incomplete combustion, and some studies have been made of this aspect [6].

The effect of biomass moisture content on combustion and emissions has been the subject of a number of investigations. However, a difficulty is that it can vary depending on the initial moisture content in the wood and the humidity of the surrounding air [7]. In the case of logs, moisture can be lost or gained via the end grain so that the moisture is unevenly distributed throughout the $\log$. [8] There is an issue that the practical definition of moisture content into loosely defined categories such as kiln dried, seasoned and freshly harvested, is at present insufficient to define the use of wood as a fuel. Some schemes have been implemented in which the wood is certified to have a moisture content less than $20 \%$, but so far there is still limited data available from real stove studies about their impact. For many people, the sight and smell of wood smoke curling out of a chimney brings back fond memories of hearth and home [9]. Wood is a renewable resource, unlike fossil fuels such as oil, coal, and gas, which are non-renewable. In fact, if firewood is harvested in a sustainable way, woodlots can provide an abundant source of fuel for years to come. [10] Unfortunately, smoke from wood burning stoves and fireplaces can be a significant source of air pollution, negatively impacting public health, and the environment. People can reduce the amount of smoke from their wood stoves by choosing low-emission EPA-certified stoves (EPA(Environmental Protection Agency) Certified Wood Stoves states All wood stoves certified under 
the 2015 New Source Performance Standards (NSPS) have been independently tested by an accredited laboratory to meet a particulate emissions limit of no more than 4.5 grams per hour. Countries following EPA standards are Europe, Canada, Australia, Singapore etc.) operating them properly, and using seasoned firewood. This will improve combustion efficiency, reduce emissions, help protect public health and the environment, and save fuel costs [11]. [12] Deploys a rocket mud stove to reduce the fuel wood usage and to improve the fuel efficiency. The rocket mud stove was first developed and successfully implemented in Uganda. It was then adopted by GTZ Kenya in 2006 in another successful programme. In Kenya, research has shown that the stoves are $60 \%$ more efficient than traditional methods of cooking. Because of its internal design it consumes firewood more efficiently than a three stone fire. This means less firewood is needed to cook the same amount of food. Also it addresses the social and local environmental consequences of fuel wood collection.

\section{A) Knapsack filter}

Gas-solid separation devices associated with pneumatic conveying systems have two functions. To recover the conveyed material as much as possible and to minimize pollution of the environment by the working material. Different separation mechanisms used based on the size of particles are: gravity settling chambers, cyclone separators, and bag type fabric filters [13]. If a bulk material consists of relatively large and heavy particles, with no fine dust, it may be possible to collect the material in a simple bin, where the solid material falls under gravity to the bottom of the bin while the gas is taken off through a suitable vent. However, if a bulk material is of slightly smaller particle size, it may be required to enhance the gravitational effect. The most common method for this is to impart spin to the gas-solid stream so that the solid particles are thrown outwards while the gas is drawn off from the center of the vortex. A cyclone separator works on this principle. If particles are fine and especially if they are also of low density, separation in a cyclone may not be fully effective, and in this case the gas-solid stream may be vented through a fabric filter. For materials containing extremely fine particles or dust, further refinement in the filtration technique may be necessary, for example, use of wet washers or scrubbers and electrostatic precipitators. In general, the finer the particles that have to be collected, the higher will be the cost of a suitable separation system [14]. Airborne dusts which may be encountered in industrial situations are generally less than about $10 \mu \mathrm{m}$ in size. Particles of this size can be taken into the body by ingestion, skin absorption, or inhalation. The former is rarely a serious problem and, although diseases of the skin are not an infrequent occurrence, it is inhalation that presents the greatest hazard for workers in a dusty environment. Particles falling in the size range of approximately $0.5-5 \mu \mathrm{m}$, if inhaled, can reach the lower regions of the lungs where they will be retained. Prolonged exposure to such dusts can cause permanent damage to the lung tissues (pneumoconiosis) symptomized by shortness of breath and increased susceptibility to respiratory infection. In view of above, information about working of bag type fabric filters, fabric materials, different types of bag type fabric filters, design considerations, maintenance of fabric filters (pulse jet type), and useful terms related with fabric filters is given in this booklet. Knapsack filter is used to particulate emissions control. In knapsack filter, the particle-laden gas flows through a number of filter bags placed in parallel, leaving the dust retained. In this Knapsack filter consisting of 5 filters. That filter has been made in Polyester. in fig 3. The first step in reviewing design criteria is determining the flow rate of the gas being filtered by the filter, which is measured in cubic meters (cubic feet) per minute. The gas volume to be treated is set by the process exhaust, but the filtration velocity or air-to-cloth ratio is determined by the filter vendor's design. The air-to-cloth ratio that is finally chosen depends on specific design features including fabric type, fibers used for the fabric, bag cleaning mechanism [15].

\section{B) Stimulated Carbon with Cellulose Nano fiber Filter}

Stimulated carbon filters are widely used to reduce odors and control emissions from greenhouses and other growing operations. The ambient air is circulated through the activated carbon filter and returned to the greenhouse or discharged outside as shown in fig 1 . Understanding the basic guidelines of how Stimulated carbon filters work will help growers use the technology with greater reliability and lower overall cost [16]. Stimulated carbon works by a phenomenon called adsorption, where the odor compound is trapped inside the Stimulated carbon and retained, but the material doing the adsorption does not change size. Adsorption differs from absorption, which also removes things, but the result is swelling. Both adsorption and absorption media have fixed capacities, meaning they hold just so much, since they are storing the material removed from the air, not destroying it. It is easier to tell what is going on with absorption, since the size increase equals the amount of material removed; with absorption, there is a weight gain, but it is hard to measure and we need to use other means to gauge the remaining life of a carbon filter. Activated carbon removes odors by offering the odor-causing compound a more attractive place to reside than circulating in the air [17]. The adsorbed state when the odor compound leaves the air and gets retained inside the activated carbon is called a lower-energy state and it is as if the molecule falls into a hole and cannot get out. New Stimulated carbon has lots of unoccupied holes and virtually every compound that passes through falls in a hole and is retained. Over time, the empty holes fill up. The molecules that are adsorbed with higher energy, sort of like weighing more, can displace the lower-energy molecules that are less tightly held, leading to molecular musical chairs.

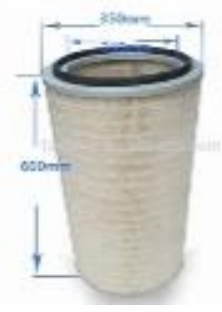


Fig. 1. Cellulose nano fibre filter with carbon

Membranes and filters can be used to separate different chemical species by allowing some species to pass while other is stopped. The selectivity of a membrane is related to the microstructure and chemistry of the membrane material. Membranes can be designed with well-define pores for size exclusion and a tailored surface chemistry in order to selectively adsorb specific solutes [18].

However, the overall methodologies exhibit some issues in achieving thermal efficiency as well as fuel efficiency that subsequently affects the system performance. Moreover the amount of toxic gases/elements released on to the environment is also too high, which causes serious health issues to millions of people all over the world. Hence to overwhelm all such issues and to gain better performance a novelty is required in this field. Therefore a Bi-folded colander framework is proposed in our work, which integrates a Knapsack filter and simulated Carbon with Cellulose Nano fiber filters are used to purify the exhaust gas. Fig 2 shows the before, after filtration condition state of cellulose carbon fibre.

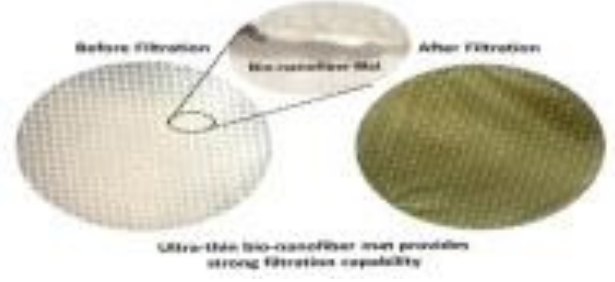

Fig. 2. illustrating filter condition state

Most dust collector filters reach an end of life when the filtration media is fully depth-loaded and can no longer be cleaned to an acceptable degree to allow design airflow with the available fan in the system. Because of the Nano fiber efficiency layer and surface loading characteristics, Nano fiber layer filters last significantly longer than traditional commodity filter elements. Longer filter life means buying new filters less frequently, saving considerable money over time. Additionally, longer filter life reduces the frequency of costly operation downtime for filter change maintenance activities.

Duration of the filter is maximum of 1years, and it can be decided through the filtration of $\mathrm{CO}, \mathrm{CO}$ ffrom IAP meter.

\section{RELATED RESEARCHES}

A. Price-Allison [19] had proposed a study has been made of the effect of fuel moisture content on emissions from a wood burning domestic stove. Two fuel types were studied: beech which is a hardwood, and spruce which is softwood. The moisture contents investigated were for a freshly felled wood, a seasoned wood and a kiln dried wood. The effect of the moisture measurement method was considered using a commercial electrical conductivity probe moisture meter which was compared with laboratory analysis by drying in an oven at $105^{\circ} \mathrm{C}$. It was shown that the probe can significantly underestimate the actual moisture content in certain cases. Correlations were made of the burning rate, the Emission Factors for the formation of gaseous and particulate pollutants as a function of the moisture content. We also studied the ratio of Black Carbon to Total Carbon (BC/TC) to obtain information on the organic content of the particles. The NOX emissions from this type of stove were only dependent on the fuel-nitrogen content and not on the moisture content.

Graydon Snider [20] had Decades of intervention programs that replaced traditional biomass stoves with cleaner-burning technologies have failed to meet the World Health Organization (WHO) interim indoor air quality target of 35$\mu \mathrm{g} \mathrm{m}-3$ for PM2.5. Many attribute these results to continued use of biomass stoves and poor outdoor air quality; though the relative impacts of these factors have not been empirically quantified. They measured 496 days of real-time stove use concurrently with outdoor and indoor air pollution (PM2.5) in 150 rural households in Sichuan, China. The impacts of stove use patterns and outdoor air quality on indoor PM2.5 were quantified. They also estimated the potential avoided cardiovascular mortality in southwestern China associated with transition from traditional to clean fuel stoves using established exposure-response relationships. Mean daily indoor PM2.5 was highest in homes using both wood and clean fuel stoves $(122 \mu \mathrm{g} \mathrm{m}-3)$, followed by exclusive use of wood stoves (106 $\mu \mathrm{g} \mathrm{m}-3$ ), and clean fuel stoves. Wood stoves emitted proportionally higher indoor PM2.5 during ignition, and longer stove use was not associated with higher indoor PM2.5. Only $24 \%$ of days with exclusive use of clean fuel stoves met the WHO indoor air quality target, though this fraction rose to $73 \%$ after subtracting the outdoor PM2.5 contribution. Reduced PM2.5 exposure through exclusive use of gas or electric stoves was estimated to prevent 48,000 yearly premature deaths in southwestern China, with greater reductions if local outdoor PM2.5 is also reduced. Clean stove and fuel interventions are not likely to reduce indoor PM2.5 to the WHO target unless their use is exclusive and outdoor air pollution is sufficiently low, but may still offer some cardiovascular issues.

Candela de la Sota [21] A cross-sectional study was conducted to examine the effectiveness of a stove intervention program to reduce indoor pollutant levels at a rural village in Senegal. Results confirmed that household air pollution in this area is mainly due to cooking activities. The installation of the Noflaye Jegg, a locally produced improved rocket stove, contributed to a significant reduction of total fine and ultrafine particulate number and $\mathrm{CO}(75,4 \%, 30,5 \%$ and $54,3 \%$, respectively) with respect to traditional stoves, but increased indoor BC concentrations $(36,1 \%)$. According to these results, improved cook stoves would have a positive effect with regard to health effects, but not for all pollutants monitored. This proves that the climate and health-relevant properties of stoves do not always scale together and highlights that both dimensions should be always considered. Alternative cook stoves focusing on the reduction of $\mathrm{BC}$ emissions should be considered to increase co-benefits on climate change mitigation. Findings also evidence that, in addition to a switch in the emission source (i.e. cook stove and/or fuel), successful strategies focused on the improvement of household air quality in Senegal should contemplate ventilation practices 
and construction materials. The majority of the improved cook stoves ( 40 out of 50 ) disseminated in 2012 in the rural village under study were in disuse, completely or partially damaged, showing that adoption and sustained use of stoves by families is plausibly the most important and challenging consideration to implement improved cook stove projects. Thus, successful strategies focused on the improvement of household air quality in Senegal and other populations of sub-Saharan Africa should include information about better ventilation practices and an appropriate education on the cooking environment.

Kaare Press-Kristensen [22] Residential heating with wood (and coal) in small stoves and boilers emits about 50 percent of the total fine particle and black carbon emissions in Europe. Furthermore, many studies have confirmed a significant emission of ultrafine particles from residential heating. In other sectors, particle emissions have been successfully reduced by particulate filters. However, filters or other flue gas cleaning systems are still not standard equipment for small stoves or boilers. Even though new stoves and boilers still pollute much more compared to other heat sources and road traffic. The purpose was to investigate the removal of particles in an electrostatic filter and a condensing flue gas system with a bag filter adapted for small stoves and boilers. This study investigates the removal efficiency in two filter systems adapted for stoves and boilers: An electrostatic filter and a condensing flue gas system with a bag filter. Measurements were done with dilution tunnels to include condensates. Measurements were performed with P-Tracks for ultrafine particles (PM0.1) and traditional particle mass collection (quartz filters) concerning fine particles (PM2.5). The collected particle mass was analyzed for elementary carbon (EC) equivalent to black carbon (soot) and analyzed for organic carbon (OC). Removal efficiencies were found comparing measurements before and after both filter systems. The two investigated filter systems efficiently remove particles, fine particles, elementary carbon, and organic carbon. The bag filter has the highest efficiency and showed a high removal of ultrafine particles as well.

Nikola Kant ova [23] had proposed to separate particulate matter before their leaving into the air because of their harmful impact on human health. It exist a lot of devices, which can separate these particles. But their implementation and operation in small heat source can be considerably difficult on finances, and often have complex maintenance. Therefore, it is important to look for solutions of reduction the producing of particulate matter with easier maintenance and also less financial difficulty. This article deals with flow modeling of particulate matter by using baffles placed in the flue tract of wood stove. Influence of baffles is observed by using CFD simulations. Decrease of particulate matter is necessary topic for air protection. Elimination of particulate matter can be achieved by various ways. But many separators are difficult on finances, and often have complex maintenance. Therefore, it is important to look for more useful solutions. This paper deals with flow modeling of particulate matter by using baffles placed in the flue tract of wood stove. Their effect was observed and analyzed by using CFD simulations. Used baffles were effective for larger particles, which were captured. Bigger amount of smaller particles escaped in the flue gas stream.

[24] During the field trial period, it was found that the design based on the original Aprovecho rocket stove (RS1) was difficult to light and the flame could not be sustained for cooking. The reason for failure of the stove to maintain a flame during cooking is that the air inlet below the grid became clogged with ash within a half an hour of lighting, effectively starving the burn area of oxygen. It is also unsafe to clear the ash from the combustion chamber when the stove is still burning.

[25] Introduced a rocket style cook stove, using potassium oxide as a catalyst. Additionally, doping potassium titanate with copper or cobalt further enhanced carbon monoxide oxidation activity. It reduces both the PM and carbon monoxide emission below the recommended limits when compared with an empty stove and a three stone fire. However several health effects are created with this catalytic rocket stove.

Thus from the above data, it is clear that the prior methodologies faces some issues with the conventional rocket stoves. [20] reduces the exclusive and outdoor air pollution sufficiently low, but still causes some cardiovascular related issues, [23] works effectively to remove the larger particles present in the exhaust gas, but fails to prevent the smaller particles from escaping through the flue gas stream. Similarly, [24] is said to be unsafe for clearing the ash from the combustion chamber, before the stove gets stop burning. [25] ends up with some health issues. So forth to deal with these issues an ecofriendly stove technology, that prevents the pollution caused with emission of exhaust gas has to be innovated.

Nordica McCarty al. [39] analyzed over The following is an initial report of the performance of three types of Rocket stoves: a single pot stove, a double pot stove, and a double pot stove with chimney, compared to both the open fire and traditional stoves commonly used in Tamil Nadu, India. The stoves were tested using the Controlled Cooking Test to measure fuel use, carbon monoxide, and particulate matter emissions made while local cooks prepare commonly made foods. Portable emissions measurement equipment created by Aprovecho Research Center was used to measure emissions made in both the lab and field. The Controlled Cooking Test series conducted on the pilot stoves in India was a positive experience. Results showed fuel and emissions savings to be substantial, and generally in line with what was expected from the laboratory design. The portable emission equipment functioned well and was easy to use and unobtrusive to the cooking process. As this technique reduced most of the emissions indoor but polluted outdoor.

Thompson al. [40] examined the effect of reduced wood smoke exposure in pregnancy on low birth weight (LBW)( Low birth weight (LBW) is defined by the World Health Organization as a birth weight of an infant of 2,499 g or less, regardless of gestational age) of Guatemalan infants in 
RESPIRE (Randomized Exposure Study of Pollution Indoors and Respiratory Effects).Pregnant women using chimney stoves had a $39 \%$ reduction in mean exposure to carbon monoxide compared with those using open fires. LBW prevalence was high at $22.4 \%$. On average, infants born to mothers who used a stove weighed $89 \mathrm{~g}$ more [95\% confidence interval (CI), -27 to $204 \mathrm{~g}$ ] than infants whose mothers used open fires after adjusting for maternal height, diastolic blood pressure, gravidity, and season of birth. The adjusted OR for LBW was 0.74 (95\% CI, 0.33-1.66) among infants of stove users compared with open-fire users. Average birth weight was $296 \mathrm{~g}$ higher (95\% CI, 109-482 g) in infants born during the cold season (after harvest) than in other infants; this unanticipated finding may reflect the role of maternal nutrition on birth weight in an impoverished region. A chimney stove reduced wood smoke exposures and was associated with reduced LBW occurrence. Although not statistically significant, the estimated effect was consistent with previous studies. As this technique reduced $39 \%$ of CO from the exhaust gas.

\section{NOVEL BI-FOLDED COLANDER FRAMEWORK}

The Rocket Stove is a clean burning and fuel-efficient cooking stove which can use thin sticks as fuel. This means that Rocket Stoves are more efficient than open fires; they use less firewood therefore reduce long-term household expenditure. The Rocket Stove's ability to use small dried branches negates the need to rely on charcoal and deforestation with its increasingly destructive environmental impact. Rocket stoves have an insulated combustion chamber which allows them to focus the heat where it is needed during the cooking process (i.e. into the cooking pot). The insulation also makes it safer to touch during and after use. Rocket stoves make cooking with fire easier, safer, and faster than with open fires. They are quicker to start, needs little tending, and can meet the specific needs of domestic and small/large scale commercial cooks. Rocket Stoves reduce the time taken to start a stove and the time to cook/boil food due their excellent fuel efficiency. A user does not have to blow air into the stove to fan the flame. Once lit, the stove fire will burn continuously unless one stops putting firewood into the stove. When compared to a 3-stone open fire, the rocket stoves cook a given quantity of food in half the time [26].

Rocket Stoves are ideal for domestic and commercial cooking and water heating purposes in many locations across - not only Zanzibar, but East Africa as a whole - where wood fuel is expensive and/or difficult to find. The firewood wood is burnt inside the rocket stove's insulated high-temperature combustion chamber Fig: 3. A simple 'elbow' shape is used to enable a good air flow and the controlled use of firewood resulting in the full combustion (including the harmful smoke) and efficient use of the resultant heat [27].

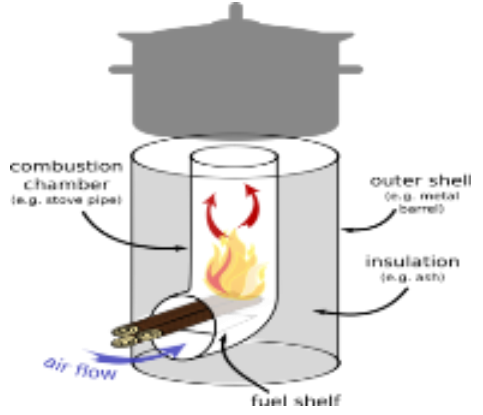

Fig. 3. Simple design of rocket Stove

In rocket stove is the high temperature reached high efficiency stove. Wood is the fuel of this stove. Burning the wood in the bottom of the stove; the heat will flow to top of the stove in Figure: 2. Wood burning contributes pollution to the environment in the form of the smoke emitted as the wood is burned [28]. The smoke released serves as a pollutant to the outside, particular in winter months, and can also pollute the air inside the home if not properly vented, causing smoke to build up in your rooms. Combustion is created by wood and coal fires, but also by regular activities - such as burning candles, using electric toasters and gas cooking. Combustion produces tiny particulate matter. This can also come from dusting and vacuuming. Gases including carbon dioxide $\left(\mathrm{CO}_{2}\right)$, nitrogen dioxide $\left(\mathrm{NO}_{2}\right)$ and carbon monoxide $(\mathrm{CO})$ and Volatile organic compounds. Volatile organic compounds (VOCs) are chemicals found in a wide variety of materials. They are produced when cooking and using heating appliances, such as wood burners and non-electric space heaters. VOCs evaporate into the air at room temperature, forming vapors that we breathe, So that we used proposed methodology in fig 4.

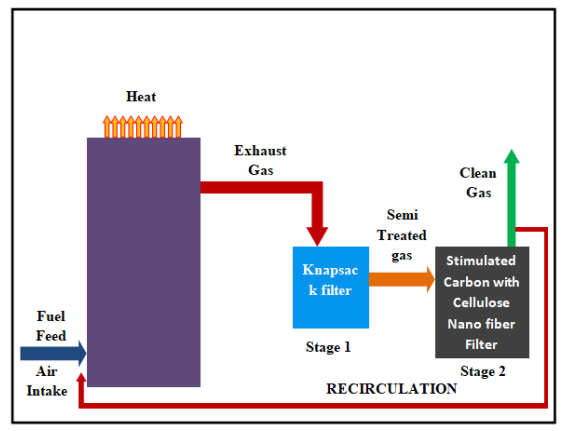

Fig. 4. Proposed Methodology

\section{A) Design of Rocket Stove}

The size of the stove is determined using the size of the saucepan that will be used for cooking in it as shown in fig 5 . The saucepan capacity is therefore the first thing that should be determined. This manual details the dimensions for 3 sizes for cooking pots around which the stove will be based. For bigger cooking pots the sizes can be adjusted accordingly [29].

\section{1) Design parameters}

\section{Dimensions:}

i.

$420 \mathrm{~mm}$
Height of combustion chamber (elbow) $=$ 
ii. Cross section of elbow at inlet $=120 \mathrm{~mm} * 120 \mathrm{~mm}$.

iii. Diameter of outer casing $=240 \mathrm{~mm}$.

iv. External Diameter of outercasing $=500 \mathrm{~mm}$

V. Thickness of material used $=1.2 \mathrm{~mm}$.

vi. Material for setup = mildsteel

vii. $\quad$ Insulation material $=$ Siporex

viii. Cross section of wood fuel $=120 \mathrm{~mm} * 30 \mathrm{~mm} * 30 \mathrm{~mm}$

ix. Weight of setup $=8.778 \mathrm{~kg}$
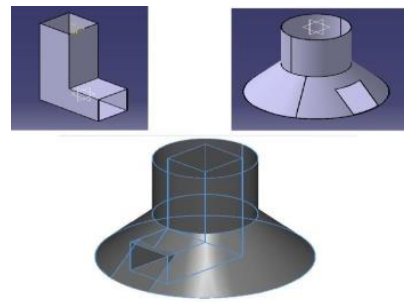

Fig. 5. CATIA model of cook stove-2

The efficiency of a stove is usually defined as the ratio of heat transferred to the cooking medium to heat supplied by fuel. The stove efficiency could be evaluated by a number of standard methods such as Constant Heat Output. Constant Temperature Rise Method, Constant Time Method, and Water Boiling Test. Of these, the Water Boiling Test appears to be most commonly used; this test method is used in the present study as well.
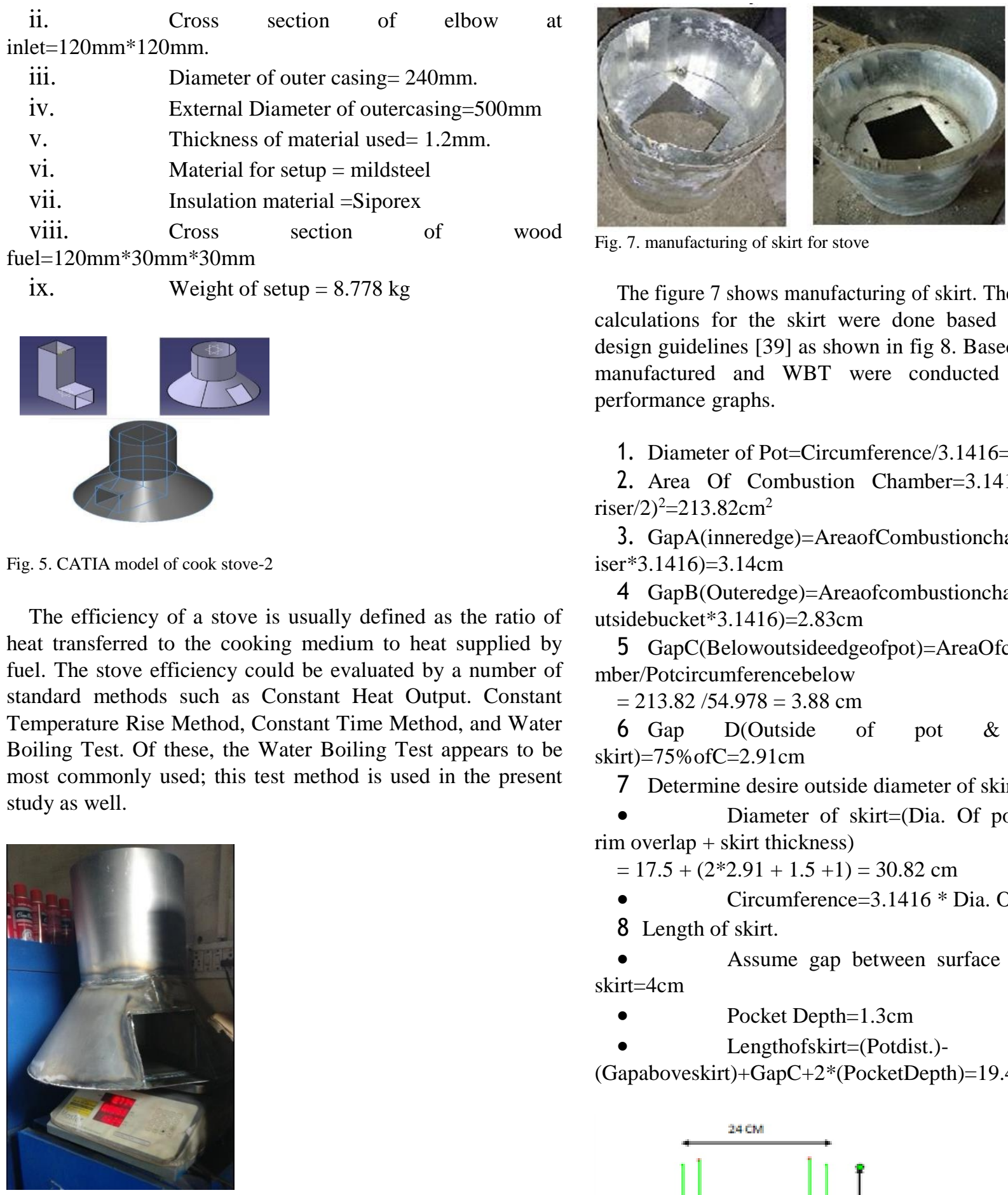

Fig. 7. manufacturing of skirt for stove

The figure 7 shows manufacturing of skirt. The design and gap calculations for the skirt were done based on Aprove cho design guidelines [39] as shown in fig 8. Based on that skirt is manufactured and WBT were conducted to obtain the performance graphs.

1. Diameter of Pot $=$ Circumference $/ 3.1416=17.5 \mathrm{~cm}$

2. Area Of Combustion Chamber $=3.1416$ (Diameter of riser $/ 2)^{2}=213.82 \mathrm{~cm}^{2}$

3. GapA(inneredge $)=$ AreaofCombustionchamber/(Dia.OfR iser*3.1416) $=3.14 \mathrm{~cm}$

$4 \mathrm{GapB}($ Outeredge $)=$ Areaofcombustionchamber/(Dia.Ofo utsidebucket*3.1416) $=2.83 \mathrm{~cm}$

$5 \mathrm{GapC}($ Belowoutsideedgeofpot $)=$ AreaOfcombustioncha mber/Potcircumferencebelow

$$
=213.82 / 54.978=3.88 \mathrm{~cm}
$$

6 Gap D(Outside of pot \& inside of skirt $)=75 \%$ ofC $=2.91 \mathrm{~cm}$

7 Determine desire outside diameter of skirt.

- Diameter of skirt=(Dia. Of pot $)+(2 *$ gap $D+$ rim overlap + skirt thickness)

$$
=17.5+(2 * 2.91+1.5+1)=30.82 \mathrm{~cm}
$$

- $\quad$ Circumference=3.1416* Dia. Of skirt

8 Length of skirt.

$\begin{array}{ll}\begin{array}{l}\text { - } \\ \text { skirt }=4 \mathrm{~cm}\end{array} & \text { Assume gap between surface and top of the } \\ \text { - } & \text { Pocket Depth }=1.3 \mathrm{~cm} \\ \text { - } & \text { Lengthofskirt=(Potdist. }) \text { - } \\ \text { (Gapaboveskirt })+ \text { GapC }+2 *(\text { PocketDepth })=19.4 \mathrm{~cm}\end{array}$

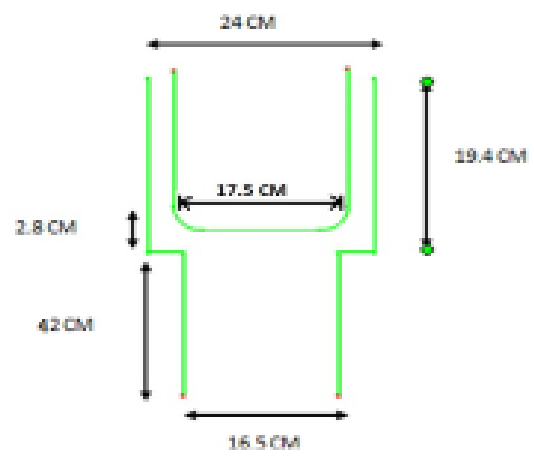

Fig. 8. Line diagram of skirt showing outlook around pot 


\section{3) Design of exhaust pipe}

A) Calculation of velocity of exhaust gas

B) Calculation of flow rate

C) Calculation of exhaust pipe diameter

\section{A) Calculation of velocity of exhaust gas:}

The continuity, momentum, and ideal gas equations can be combined and solved to give the following expression for exhaust pipe inlet velocity (see Appendix B for details):

$$
V=\sqrt{\frac{2 g h\left(\frac{\left.T_{1}-T_{2}\right)}{T_{2}}\right.}{\left(\frac{P_{1}}{P_{2}}\right)^{2}-1+\frac{F H}{4 D}\left(1+\frac{P_{1}}{P_{2}}\right)^{2}}}
$$

For inputs,

(Velocity of exhaust gas) V=?

(Height of the upper skirt) $\mathrm{h}=19.4 \mathrm{c} \mathrm{m}$,

(Chamber diameter) $\mathrm{D}=16.5 \mathrm{c} \mathrm{m}$,

(Initial temperature) $\mathrm{T}_{1}=100^{\circ} \mathrm{C}$,

(Final temperature) $\mathrm{T}_{2}=95^{\circ} \mathrm{c}$,

(Atmospheric pressure) $\mathrm{p} 2=1013.25 \mathrm{pa}$,

(Acceleration due to gravity) $\mathrm{g}=0.981 \mathrm{~cm} / \mathrm{s} 2$,

(Relative ideal gas constant) $\mathrm{R}=287 \mathrm{~J} / \mathrm{kg} \mathrm{K}$, and

(Force) $\mathrm{F}=0$

Substituting all the values in above equation we get,

(Velocity of exhaust gas) $\mathrm{V}=1.4 \mathrm{~cm} / \mathrm{s}$

\section{B) Calculation of flow rate:}

$\mathrm{Q}=\left(\mathrm{A}_{2}-\mathrm{A}_{1}\right) \mathrm{V}$

Q: Flow Rate of exhaust gas $\left(\mathrm{cm}^{3} / \mathrm{s}\right)$

$\mathrm{A}_{1}$ : area of combustion chamber $\left(\mathrm{cm}^{2}\right)$

$\mathrm{A}_{2}$ : area of upper skirt $\left(\mathrm{cm}^{2}\right)$

$\mathrm{V}$ : Velocity $(\mathrm{cm} / \mathrm{s})$

$\mathrm{Q}=(302.5-213.5) * 1.4$

$\mathrm{Q}=124.6 \mathrm{~cm}^{3} / \mathrm{s}$

\section{C) Calculation of exhaust pipe diameter:}

$$
\begin{aligned}
\mathrm{D}_{\mathrm{EXT}} & =\sqrt{\frac{4 \times \text { flowrate }}{3.14 \times \text { velocity }}} \\
& =\sqrt{\frac{4 \times 124.6}{3.14 \times 1.4}}
\end{aligned}
$$

$\mathrm{D}_{\text {EXT }}=10.6 \mathrm{~cm}$

Diameter of exhaust pipe is $10.6 \mathrm{~cm}$

Height of the exhaust pipe that has to be fitted in stove is $1 / 2$ of the height of upper skirt

Height $=1 / 2 * 19.4=9.7 \mathrm{~cm}$

\section{4) Determination of Burning Capacity Rate}

If the fuel burning rate is not given by the manufacturer, the cook stove is operated with method described below and the same shall be used to estimate the burning capacity of the Cook stove. Stack the fuel in a honey comb fashion in combustion chamber as given in up to $3 / 4$ of the height for continuous feeding type Cook stove, or in a pattern recommended by the manufacturer.

i. Weigh the Cook stove with fuel, let the mass be $\mathrm{M} 1 \mathrm{~kg}$.

ii. Sprinkle 10 to $15 \mathrm{ml}$ of kerosene on the fuel from the top of Cook stove /fire box mouth.

iii. After half an hour of lighting weigh the stove with fuel residues again and let the mass be M2kg.

Then calculate the burning capacity of the Cook stove as heat input per hour as follows:

Burning capacity rating $=2(\mathrm{~m} 1-\mathrm{m} 2) \mathrm{kg} / \mathrm{hr}$. Heat input per hour $=2\left(\mathrm{~m}_{1}-\mathrm{m}_{2}\right) \times \mathrm{CV} \mathrm{kcal} / \mathrm{hr}$.

Where, $\mathrm{m} 1$ =the initial mass of the Cook stove with test fuel in $\mathrm{kg}$,

$\mathrm{m} 2$ = the mass of the Cook stove with fuel residues, after burning the test fuel for half an hour in $\mathrm{kg}$,

$\mathrm{CV}=$ Calorific value of the test fuel in $\mathrm{kcal} / \mathrm{kg}$.

5) Calculations for without insulting liner material

\begin{tabular}{lcc} 
Table 1: wood sample weight. \\
\cline { 2 - 3 } Si. No. & $\begin{array}{c}\text { Weight of wood before } \\
\text { drying }\end{array}$ & $\begin{array}{c}\text { Weight of wood after } \\
\text { drying }\end{array}$ \\
\hline 1. & 80 & 76.8 \\
2. & 82 & 76.2 \\
3. & 82.1 & 78.2 \\
Total & $\mathbf{2 4 4 . 1}$ & $\mathbf{2 3 1 . 2}$ \\
\hline
\end{tabular}

6) Calculations for moisture content test

$\%$ moisture content $=\sum(W-d) / \sum d^{*} 100$

$\mathrm{W}=$ weight of wet wood (before weight)

$\mathrm{d}=$ weight of dry wood (after weight)

$\%$ moisture content $=\sum(244.1-231.2) / \sum 231.2 * 100$

$$
=5.57 \%
$$

\section{7) Determination of Burning Capacity Rate}

$\mathrm{m} 1=$ the initial mass of cook stove with test fuel $=8.778+$ $(76.8+76.2+78.2)$

$$
=9.0092 \mathrm{~kg}
$$

$\mathrm{m} 2=$ the initial mass of cook stove with fuel residues, after burning the test fuel for half an hour $=8.778+(0.0341)$ $=8.8121 \mathrm{~kg}$

Burning Capacity Rating 2 (M1 - M2) kg/hr. $=2(9.0092-8.8121)$

\section{Burning Capacity Rating $=0.3942 \mathrm{kcal} / \mathrm{hr}$. Heat input per hour: \\ Heat input per hour $=2(\mathrm{M} 1-\mathrm{M} 2) * \mathrm{CV} \mathrm{kcal} / \mathrm{hr}$. $=2(9.0092-8.8121) * 4302.103$}

\section{Heat input per hour $=1695.88 \mathrm{kcal} / \mathrm{hr} . \quad 2000$}

From above calculations, as per BIS 13512, pot selection dimensions will be as follows: 
Table 2: Aluminum vessels for thermal efficiency

\begin{tabular}{|c|c|c|c|c|c|}
\hline \multicolumn{2}{|c|}{ Si. Heat Input } & \multirow{2}{*}{$\begin{array}{c}\text { Vessel } \\
\text { Diameter } \\
\text { (Ext) } \mathrm{mm}( \pm \\
5 \%)\end{array}$} & \multirow{2}{*}{$\begin{array}{l}\text { Vessel } \\
\text { Height } \\
\text { (Ext) } \\
\text { Mm ( } \pm \\
5 \%)\end{array}$} & \multicolumn{2}{|c|}{ Total MassMass of } \\
\hline No. & $\begin{array}{c}\text { Rate } \\
\mathrm{kcal} / \mathrm{h}\end{array}$ & & & $( \pm 20 \%)$ & Vessel kg \\
\hline 1 & $\begin{array}{l}\text { Up to } \\
2000\end{array}$ & 180 & 100 & 356 & 2 \\
\hline 2 & $\begin{array}{l}2001 \text { to } \\
2800\end{array}$ & 205 & 110 & 451 & 2.8 \\
\hline 3 & $\begin{array}{c}2801 \\
\text { to } \\
3200\end{array}$ & 220 & 120 & 519 & 3.7 \\
\hline
\end{tabular}

From above calculations, as per BIS 13512, pot selection dimensions will be as follows:

1. Vessel diameter $=180 \mathrm{~mm}$

2. Vessel height $=100 \mathrm{~mm}$

\section{8) Combustion Chamber}

A combustion chamber is an enclosed space inside of a combustion Stove in which a fuel and air mixture is burned in fig 9. Where wood is burned and provision of updraft to maintain the fire. Burning fuel releases a gas that increases in temperature and volume [30]. When you heat a gas, the atoms in the gas start bouncing off each other with more energy and vigor. The hard bouncing causes them to get thrown out farther and the whole gaseous cloud expands.
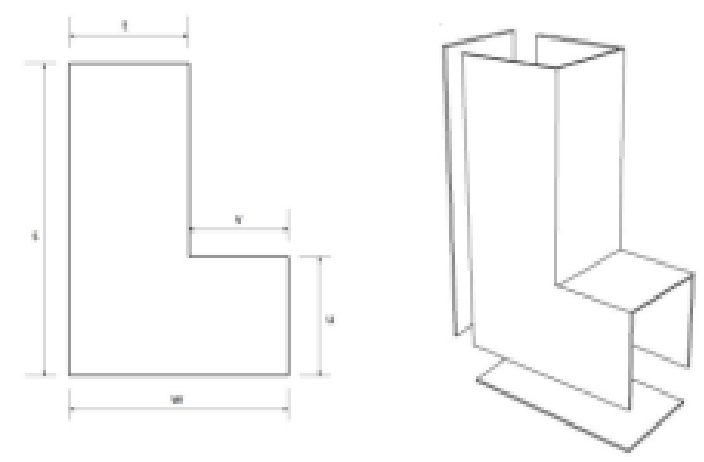

Fig. 9. Combustion chamber

\section{9) Thermal insulator}

Thermal insulation is the process of insulating material from transferring heat between the materials that are in thermal contact [31] as shown in fig 10. Thermal insulation is measured by its thermal conductivity. Low thermal-conductive materials are used for thermal insulation. Besides thermal conductivity, density and heat capacity are also important properties of insulating materials. The thermal insulators are used to reduce the heat loss of the stove. In our project we used Ceramics Thermal Insulation.

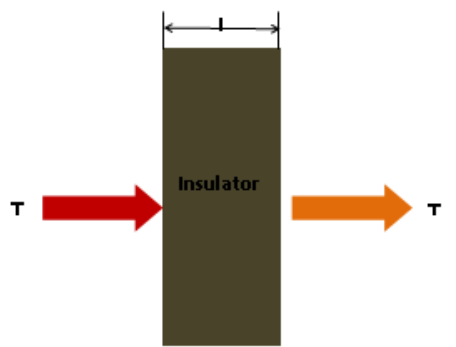

Fig. 10. Het flow of Insulator

$$
\begin{array}{r}
q=\frac{-k \cdot\left(T_{2}-T_{1}\right)}{L} \\
L=\frac{-k\left(T_{2}-T_{1}\right)}{q}
\end{array}
$$

$\mathrm{k}=0.120 \mathrm{w} / \mathrm{m}^{\circ} \mathrm{c}$

$\mathrm{q}=1695.88 \mathrm{kcal} / \mathrm{hr}$.

$\mathrm{T}_{1}=1100^{\circ} \mathrm{C}$

$\mathrm{T}_{2}=320^{\circ} \mathrm{C}$

$L=\frac{-0.120(320-1100)}{1695.88}$

$\mathrm{L}=5.54 \mathrm{~cm}$

Where;

$K$ is the thermal conductivity of the ceramic layer (Siporex). $T_{1}$ and $T_{2}$ is the temperature of the both sides of insulation layer.

$L$ is the thickness of the insulation layer.

B) Discussion Over Design

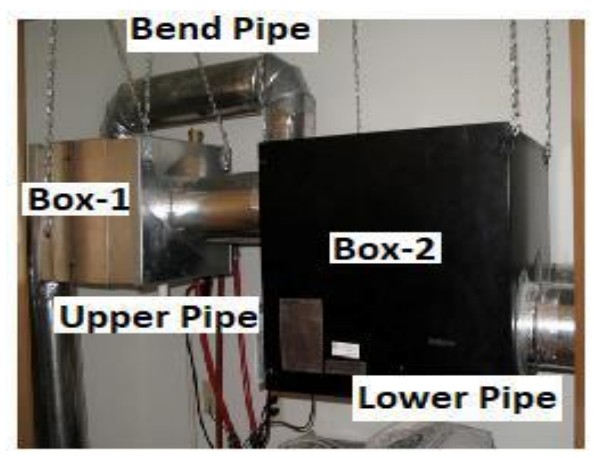

Fig. 11. design parameters

\section{a) LOWER PIPE}

Purpose:

As the end of the exhaust pipe is fitted into the lower pipe.

Now the lower pipe is attached to the box 2 .

Function:

Function of the lower pipe is to allow the passage of exhaust gas for further proceedings.

Length of pipe is $60 \mathrm{~cm}$

Diameter of the pipe: $10.6 \mathrm{CM}$

Fitted at $8.1 \mathrm{~cm}$ height from the origin of box 2. (x, y, z) $(8.1,0,8.1) .(2.8+1 / 2(\mathrm{dia}))$. 


\section{b) Box 2}

Purpose:

Purpose if the box is to carry out knapsack filter process.

As it is an closed system which doesn't allow any air to enter

Function:

Function of this box is to carry out first stage filtering process (knapsack filter).

So in first stage particular matter has being removed.

It is used to particulate emissions control, the particle-laden gas enter into the box 2 , in which a number of filter bags placed in parallel, leaving the dust retained. In this it consists of 5 filters. That filter has been made in Polyester.

Now the semi treated gas passes to the box 1 via upper pipe.

Size of the box is $60 \mathrm{~cm} \times 60 \mathrm{~cm} 60 \mathrm{~cm}$.

\section{c) Upper pipe along with bend pipe:}

Purpose:

Upper pipe is mainly used for transmission of exhaust gas from box 2 to box 1.

As the pipes are in cylindrical shapes so as to avoid losses such as edge loss, contraction losses,

Expansion losses.

Fitting calculation:

As it is fitted over some height in box 2, as the reason behind is for avoiding pressure loss and so as to get a proper suction so as to proceed further.

Length of pipe is $60 \mathrm{~cm}$.

Dia of the pipe is $10.6 \mathrm{~cm}$. (Same as the lower pipe to avoid sudden losses mainly pressure).

Fitting of the pipe is at the height of $-8.1 \mathrm{~cm}$ from the origin of box 2 (x, y, z) (-8.1, 0,-8.1).

Bend pipe is fitted for bypass of exhaust gas; it is connected with upper pipe at a distance of $8.1 \mathrm{~cm}$ from box 2 .

Bend pipe is being tilted to a $45^{\circ}$ so as to avoid losses. Now the pipe is fitted over the upper portion of box 1 at a distance of $(\mathrm{x}, \mathrm{y}, \mathrm{z})(-8.1,8.1,0)$.

Function:

It is communication way for the semi treated gas that has to be further processed into box 1 for further filtration.

Diameter of the pipe is same as exhaust pipe that is $10.6 \mathrm{~cm}$.

\section{d) BOX 1}

\section{PURPOSE:}

Box 1 mainly carry outs stage 2 process, which is mainly used for filtration of chemical compositions like $\mathrm{CO}, \mathrm{CO}_{2}$ and hydrocarbons.

\section{FUNCTION:}

Filtrations are mainly performed using cellulose Nano fiber filter. So in this cellulose will act like a catalyst for the removal of carbon contains from the gas. So chemical reaction takes place inside it which is discussed in below sections (3.2.2).

So now the gas coming out is free from chemical compositions and it has being recirculate further for the process efficient execution.

Size of the box $50 \mathrm{~cm} \times 50 \mathrm{~cm} \times 50 \mathrm{~cm}$.
As box 1 is fitted slightly higher than box 2 (height gap of $5 \mathrm{~cm})$.

Upper pipe will be fitted at a height of $14.1 \mathrm{~cm}$ from the origin of box $1 .(5+2.8+(1 / 2 *$ dia $))$.

\section{Recirculating pipe:}

The pipe running below the box 1 is used for recirculation of clean gas that contains oxygen for process, so as to obtain good fuel efficiency.

Diameter of the pipe is $10.6 \mathrm{~cm}$.

Fitting of the pipe is done at a height of $8.1 \mathrm{~cm}$ from the bottom origin. $(\mathrm{x}, \mathrm{y}, \mathrm{z})(0,8.1,8.1)$

Pipe will be connected with an elbow of $45^{\circ}$.

1) Outer Shell is defined as the outer layer of the Rocket stove. It is used to cover the insulation.

2) Firewood tray is used to holding the wood to feed the fuel to combustion chamber.

3) Exhaust pipe is used to exit the flue gas.

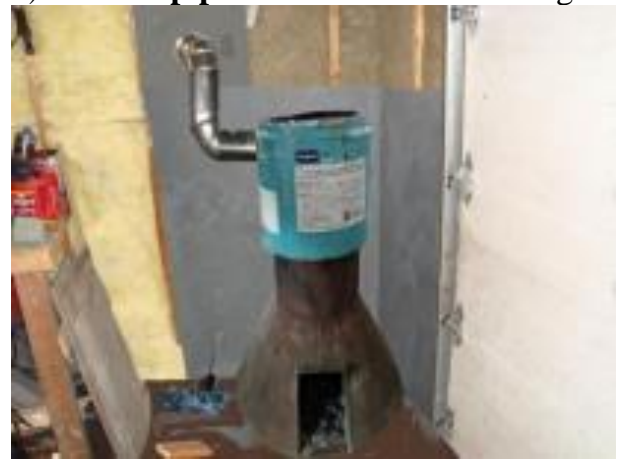

Fig. 12. real time proposed rocket stove

\section{4) Bi-folded Colander framework}

As by the name Bi-folded colander, the framework deals with two filters: Knapsack and simulated Carbon with Cellulose Nano fiber filters to perform effective removal/filtering of $\mathrm{PM}, \mathrm{CO}$ and other toxicities from the emitted gas/smoke. Initially the smoke is allowed to pass through the knapsack filter, where the particular matter gets filtered/removed. The smoke is then moved via simulated Carbon with Cellulose Nano fiber filters. Here the major reduction process is carried out, i.e., the toxic chemicals exist in the emitted gas/smoke is filtered and is removed. Finally the smoke with reduced toxicity is allowed to exhaust. The brief narration regarding the functioning of filters are given as follows:

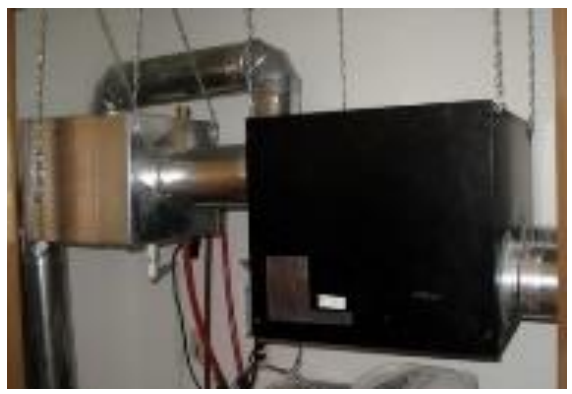

Fig. 13. design setup 


\section{5) Design of Knapsack filter}

Knapsack filter is used to particulate emissions control. In knapsack filter, the particle-laden gas flows through a number of filter bags placed in parallel, leaving the dust retained. In this Knapsack filter consisting of 5 filters. That filter has been made in Polyester. The first step in reviewing design criteria is determining the flow rate of the gas being filtered by the filter, which is measured in cubic meters (cubic feet) per minute. The gas volume to be treated is set by the process exhaust, but the filtration velocity or air-to-cloth ratio is determined by the filter vendor's design [32]. The air-to-cloth ratio that is finally chosen depends on specific design features including fabric type, fibers used for the fabric, bag cleaning mechanism, and the total number of compartments, to mention a few. Figure 14 depicts a number of these design features. A thorough review of filter design plans should consider the following factors.

Physical and chemical properties of the dust are extremely important for selecting the fabric that will be used. These include size, type, shape, and density of dust; average and maximum concentrations; chemical and physical properties such as abrasiveness, explosiveness, electrostatic charge, and agglomerating tendencies. For example, abrasive dusts will deteriorate fabrics such as cotton or glass very quickly. If the dust has an electrostatic charge, the fabric choice must be compatible to provide maximum particle collection yet still be able to be cleaned without damaging the bags.

Predicting the gas flow rate is essential for good Filter design [33]. The average and maximum flow rate, temperature, moisture content, chemical properties such as dew point, corrosiveness, and combustibility should be identified prior to the final design. If the Filter is going to be installed on an existing source, a stack test could be performed by the industrial facility to determine the process gas stream properties. If the Filter is being installed on a new source, data from a similar plant or operation may be used, but the Filter should be designed conservatively (large amount of bags, additional compartments, etc.). Sometimes, heavy dust concentrations are handled by using a Filter in conjunction with a cyclone pre-cleaner, instead of building a larger filter. Once the gas stream properties are known, the designers will be able to determine if the Filter will require extras such as shell insulation, special bag treatments, or corrosion-proof coatings on structural components .Fig 14 states the condition state of knapsack filter.

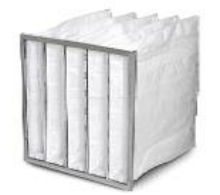

BEFORE PROCESS

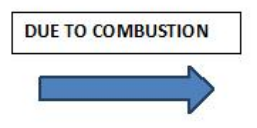

Fig. 14. Knapsack filter

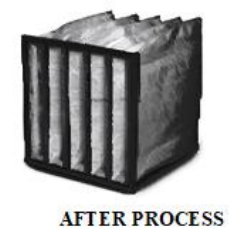

Once dust and gas stream properties have been determined, filter choice and special treatment of the filter can be properly made. For example, if the process exhaust from a coal-fired boiler is $400^{\circ} \mathrm{F}\left(204^{\circ} \mathrm{C}\right)$, with a fairly high sulfur oxide concentration, the best choice might be to go with woven glass bags that are coated with silicon graphite or other lubricating material such as Teflon.

\section{6) Design of Stimulated Carbon with Cellulose Nano fiber Filter}

The simulated Carbon with Cellulose Nano fiber filters are mainly contains two types of filters. They arranged parallel to each other's.

\section{a) Simulated Carbon Filter}

Simulated carbon can be derived from many different sources and produced in varying production processes. The raw materials used, simulated process, and process parameters determine the physical properties and performance characteristics of the resulting carbon. Modifying these activation properties determines the porosity and pore volume distribution in the carbon. The goal of this thesis is to detail a mass balance on the production of simulated carbon and develop quick screening methods to observe and compare the effects of different precursor materials, chemical reagents, and process variables on this production process. Activated carbon is defined as a carbonaceous material with a large internal surface area and highly developed

Porous structure resulting from the processing of raw materials under high temperature reactions. It is composed of $87 \%$ to $97 \%$ carbon but also contains other elements depending on the processing method used and raw material it is derived from. Simulated carbon's porous structure allows it to adsorb materials from the liquid and gas phase. Its pore volume typically ranges from 0.20 to $0.60 \mathrm{~cm}^{3} / \mathrm{g}$, and has been found to be as large as $1 \mathrm{~cm}^{3} / \mathrm{g}$. Its surface area ranges typically from 800 to $1500 \mathrm{~m}^{2} / \mathrm{g}$ [2] but has been found to be in excess of $3,000 \mathrm{~m}^{2} / \mathrm{g}$. The surface area contains mostly microspores with pore diameters smaller than $2 \mathrm{~nm}$. [3] 2 these favorable properties make simulated carbon a popular adsorbent for many applications Carbon that has been processed to make it extremely porous with a large surface area available for absorption or chemical reactions. Commonly used in air purifiers for odor absorption of many airborne pollutants. Cellulose Nano fiber filters are very sensitive filter to filter the Nano particles.

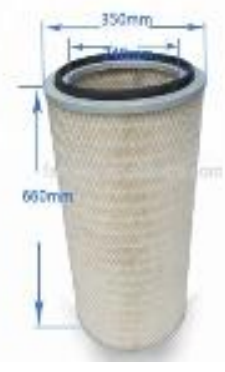

Fig. 15. Stimulated Carbon with Cellulose Nano fiber Filter 


\section{WORKING PROCESS}

In rocket stove is the high temperature reached high efficiency stove. Wood is the fuel of this stove. Burning the wood in the bottom of the stove; the heat will flow to top of the stove. Wood burning contributes pollution to the environment in the form of the smoke emitted as the wood is burned. The smoke released serves as a pollutant to the outside, particular in winter months, and can also pollute the air inside the home if not properly vented, causing smoke to build up in your rooms. Combustion is created by wood and coal fires, but also by regular activities - such as burning candles, using electric toasters and gas cooking. Combustion produces tiny particulate matter. This can also come from dusting and vacuuming. Gases including carbon dioxide $\left(\mathrm{CO}_{2}\right)$, nitrogen dioxide $\left(\mathrm{NO}_{2}\right)$ and carbon monoxide $(\mathrm{CO})$ and Volatile organic compounds. Volatile organic compounds (VOCs) are chemicals found in a wide variety of materials. They are produced when cooking and using heating appliances, such as wood burners and non-electric space heaters. VOCs evaporate into the air at room temperature, forming vapors that we breathe, So that we used proposed methodology.

The Exhaust gas is flow through the exhaust pipe to knapsack filter. Knapsack filters are used for particulate emission reduction applications. Knapsack filter s can be designed to collect particles in the sub micrometer range with 99.9\% control efficiency. They are occasionally used to remove particles from exhaust air streams generated by cooking processes where the clean air is recirculate back into the next purification process. Knapsack filter have been used for filtering fly ash in fossil-fuel fired boilers, municipal and hazardous waste incinerators, and a number of other industrial processes. The rapid growth in the use of knapsack filter for particulate control has been aided by EPA's changing the definition of particulate matter from total particulate matter to that fraction with a mean aerodynamic diameter of 10 micrometers or less $\left(\mathrm{PM}_{10}\right)$.

After that the exhaust gas flow to next level filter is called simulated Carbon with Cellulose Nano fiber filter. In this section they had two filters like, carbon filter and Cellulose Nano fiber filter. While activated carbon can adsorb hundreds of different chemicals and odors, it cannot remove everything. Carbon is not especially great at removing some common chemicals such as formaldehyde, or hydrogen sulfide. In these situations, the carbon may be impregnated with potassium iodide or blended with active alumina to increase absorption qualities. This means that all of the tiny spaces and crevices within the carbon are holding an added chemical that now reacts with and neutralizes the airborne formaldehyde or hydrogen sulfide, rather than the carbon, VOC (Volatile organic compounds), nitrogen oxides, sulfur oxides, carbon dioxide, metal particles, Dioxins, and also odors itself removing it. Then passing the exhaust gas through the Cellulose Nano fiber filter. It wills filtration the Nano size particle, after that purified air can flow to outside of the Cellulose Nano fiber filter.
In final stage the purified gas can some amount of heat energy $\left(Q_{c}\right)$. That wasted heat energy is used for the burning process. The waste heat was recirculating to intake. So that fire point of the fuel will quickly reach. So we get the more efficiency.

$$
\begin{aligned}
& \mathrm{C}_{6} \mathrm{H}_{12} \mathrm{O}_{6}+6 \mathrm{O}_{2}=6 \mathrm{CO}_{2}+6 \mathrm{H}_{2} \mathrm{O} \\
& \text { Wood (sugar) oxygen carbon dioxide }
\end{aligned}
$$

water

$$
\mathrm{RCH}_{2} \mathrm{OH}+\mathrm{CO}_{2} \longrightarrow 2 \mathrm{CO}+\mathrm{O}_{2} \longrightarrow 2 \mathrm{RO}_{2}
$$

$\mathrm{RCH}_{2} \mathrm{OH}+\mathrm{NO}_{2} \quad \mathrm{R} \mathrm{COOH}+\mathrm{H}_{2} \mathrm{O}+(1 / 2) \mathrm{N} 2$ (4)

A) IAP meter

The purpose of the IAP Meter is to quantify reductions in health-harming emissions from cooking stoves by measuring indoor concentrations of $\mathrm{CO}$ and PM.

\section{1) Features}

- Measures concentration of carbon monoxide and PM 2.5

- Includes backpack and snorkel tube for exposure monitoring

- Three sample frequency modes:

Fast Mode: Sample period: 9 seconds Battery life: 3 days

Med Mode: Sample period: 51 seconds Battery life: 2 weeks $\mathrm{CO}$ over-sampling for noise filtration

Slow Mode: Sample period: 9.7 minutes Battery life: 1 month $\mathrm{CO}$ over-sampling for noise filtration

- Serial Port output for live display and communication: RS-232/USB adapter Compatible with Live graph software for computer display

- LED indicator light: 5 second blink indicates the IAP Meter is on Solid light indicates setup mode

\section{2) IAP meter working}

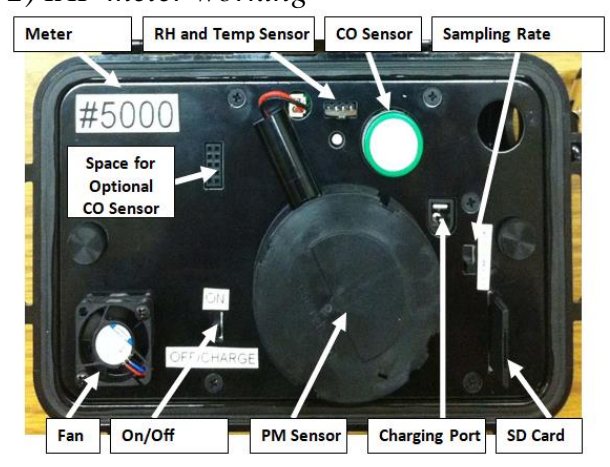

Fig. 16. IAP meter

The box contains two sensors, a fan, control circuitry, a rechargeable battery, a memory stick (SD card). The control circuitry turns the sensors on and begins recording the signal they output. In order to save battery life, the fan and sensors are turned on momentarily to take a sample, and then turned off again. The fan draws an air sample through the box so that pollutants can be accurately measured. The box stays closed when testing. At the end of a test, the meter is turned off and the data file is closed, allowing for data processing by a computer.

The CO sensor is an electrochemical cell. When exposed to 
$\mathrm{CO}$, the conductivity between two electrodes changes in proportion to the concentration of $\mathrm{CO}$.

The PM sensor works using optical light scattering. Inside the sensor are both a laser and a light receiver. When smoke enters the sensing chamber, the light of the laser bounces off the particles of smoke into the receiver. More light reaching the receiver indicates more smoke in the chamber. This level of light has been calibrated against a laboratory-standard nephelometer to relate the amount of reflected light to the concentration of smoke particles

The data is processed using Microsoft Excel or other similar spreadsheet software. This software analyzes the logged data, converts it into physical concentrations, and provides output in graphical and tabular form. Average concentrations as well as highest 15 minute averages are provided automatically in a format that can easily be copied into a master spreadsheet for comparison with other tests.

\section{3) Placement of the Meter}

Consistent meter placement is necessary for comparable measurements. Generally it is recommended that the meter be placed about $1.3 \mathrm{~m}$ aside the stove and $1.3 \mathrm{~m}$ up from the floor as shown in the figure 17, as that replicates a common breathing location of the cook. Some recommend 1.4 or 1.5 meters as this factor. House structure and ventilation complicates this location. When doing a before and after study in a house, it is necessary to place the meter in the same place in that house. There has been more detailed work done on recommended meter placement by the University of California

-- Berkeley.

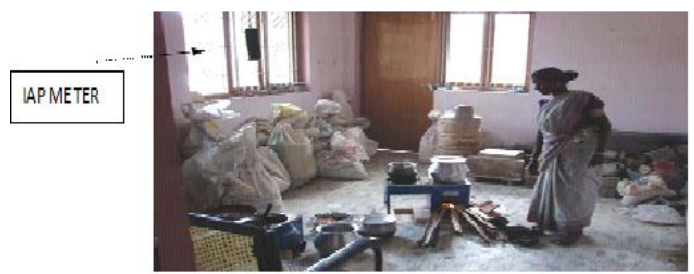

Fig. 17. placement of IAP meter

\section{B) Setting up the System}

\section{1) Additional Requirements}

Card Reader - A reader for the SD card provided with the IAP meter. This is required for transferring the data to a computer. Some computers are equipped with this drive already.

Live-Output Cables - The cables provided with the IAP meter 5000 series are connected and plugged into a computer to view live data output from the meter as well as enter the calibration menu. They are a DIN-serial cable, which is plugged directly into the meter and a serial-USB cable, which is plugged into the computer.
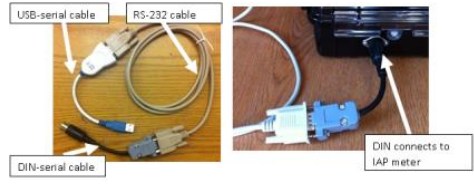

Fig. 18. cables used in IAP meter
Software - The data can be processed on Windows, Mac, and Linux operating systems using Microsoft Excel or other similar spreadsheet software. There are two versions of spreadsheet software, one with Visual Basics Macros and one without Visual Basic Macros. The data processing software with Visual Basics Macros only works on PCs with Microsoft Excel 2003 and newer. The current data processing software and other software for using the meter in live- output mode are included in the IAP Meter Software

Folder on the SD card. You may also go to www.aprovecho.org and download the data processing software for series 5000 IAP meters.

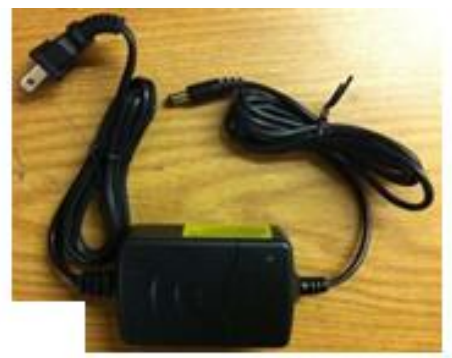

Fig. 19. power chord

Power Cord for Charger - The charger comes with a power cord with a US-style plug. If this does not fit local outlets, a simple adapter can be used with the cord provided.

\section{2) Software Folder}

There is an IAP Meter Software Folder on the SD card. It contains this instruction manual, data processing spreadsheets, Terre term (program used for connecting the meter directly to computer), and Live graph (for graphing the output). Before using the IAP Meter, copy or transfer this folder to your computer hard drive. In addition, create a folder on your $\mathrm{C}: \mathrm{I}$ drive called C:IAP-Outputl. This is where you will copy all .csv files from your meter.

\section{3) Meter Setup}

Depending on shipping method, the IAP meter may arrive with the battery disconnected. If this is the case, the battery must be installed. To install the battery, you must remove the meter panel.

Once you have removed the panel, you will see a place where the battery and its matching wire connect. Simply connect this and securely place the battery in the bottom of the case. Ensure that the wire jack makes a tight connection. Replace the panel following instructions from the video.

Turn the meter on to ensure it is functioning. When the meter is first turned on, the red LED will light up for about 5 to 10 seconds. Then it will flash about once every 5 seconds, indicating the meter is functioning. Depending on the sample speed selected, you may be able to watch the IAP meter sample. You can gently remove the top of the PM sensing chamber and see the red laser turn on every sample. You can also see the fan spin every sample. It may take up to 1 minute for the meter to start up. A third way, and the best way, to verify the meter is functioning, is to connect it to a computer through the serial port and view the output. Instructions on 
how to do this are explained in section 9 of this document.

\section{C) Running a Test}

A test involves selecting the sample rate, turning on the meter, closing the lid, taking at least 10 minutes of clean background air data, sampling, and then powering down and processing data.

When arriving at the sample location, it is a good idea to let the meter acclimate to the local temperature, especially if it is being moved from a hot car into a cool room. Let the meter sit for a few minutes with the lid open and the meter turned off, out of direct sun. The signal from the $\mathrm{CO}$ sensor is affected by temperature, so this helps to establish the proper temperature and $\mathrm{CO}$ baseline.

\section{D) Selecting the Sample Rate}

Set the sample rate switch to fast, medium, or slow sample rate. If the sample rate is switched to a different rate while the IAP Meter is on, the sample rate will not change until the device is turned off then on again.

\section{E) Live Data Output}

The IAP meter comes with an RS-232 (9 pin) computer connector cord, as well as an RS- 232/USB adapter. The IAP Meter can be connected to a computer serial port to view the raw data output, graph the output, and change the calibration constants.

If you are using a USB connection, you will need to install the proper drivers in order for the adapter to function properly. To install, copy the appropriate driver folder to your C: $\backslash$ drive. This folder is located on your software CD. It is labeled "FTDI Chip - USB Serial Adapter" - make sure to copy the appropriate 32-bit or 64-bit folder for your computer. Plug the RS-232 to USB adapter into a USB port on the computer. A window should pop up, asking you to install the driver software for the UC232R device. If it does not, then go to the Device Manager found in the "Control Panels" in the system folder, or click on the Device Manager icon installed on your desktop. Double click on the Universal Serial Bus device that has a small yellow triangle

With an exclamation mark. In the window that opens, click the "Drivers" tab at the top. Then click "Update Drivers". This will open the driver install window. While you are installing the drivers, be sure to choose the option to choose your own drivers, and select the folder you installed earlier on the C:I drive. You may have to go through the driver installation process twice before the device is recognized by your computer.

F) Serial Port Output

The IAP Meter will give an output like this when it is turned on:

\#testing:humid $\mathrm{OK}$ CO $\mathrm{OK}$ CO2....CO2 err \#IAP4000j_cell_8

\#type Cal (in 5 seconds) \#? ...starting logging \#CO initialized.

\#initializing SD card...done \#clock initialized

\#year: 2019 month: 4 day 1: hour: 17 min: $26 \mathrm{sec:} 55$

\#start time: 56159 \#make new file name:

\#new name: 2019_04_01_172655.csv \#files open

\#waits for timer \#fast sampling

\#init i2c libs....done, measure, and log

\# CalVal: XX, PB, TE, CO, PM, TO, C2 \#, 614, 0.0408, $0.0326,1.65,1$

\#\#,\#\#

Seconds, batt, adc_temp, CO, PM, humidity, top_temp 9, $81,710,111,551,47,19$

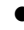

Line 1: when you see line 1, you have 5 seconds to type the word "cal" to enter setup mode and change the calibration constants

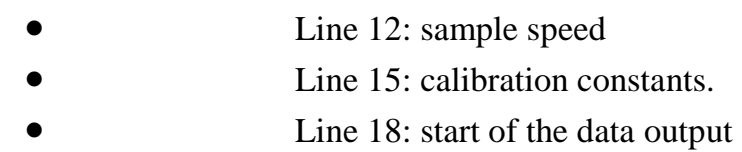

Column 1: time (seconds)

Column 2: Battery life (percent charged) Column 3:

Temperature (log units) Column 4: $\mathrm{CO}(\log$ units)

Column 5: PM (log units)

Column 6: RH (relative humidity) Column 7: Temperature (degrees $\mathrm{C}$ )

\section{G) Using the Data}

The data is provided in a columnar format so that it can be easily copied into a summary spreadsheet for comparison with other tests. Be sure to choose Paste Special - Values when transferring data to another spreadsheet. Below is an example of how data may be combined to provide the average and variation of a test series.

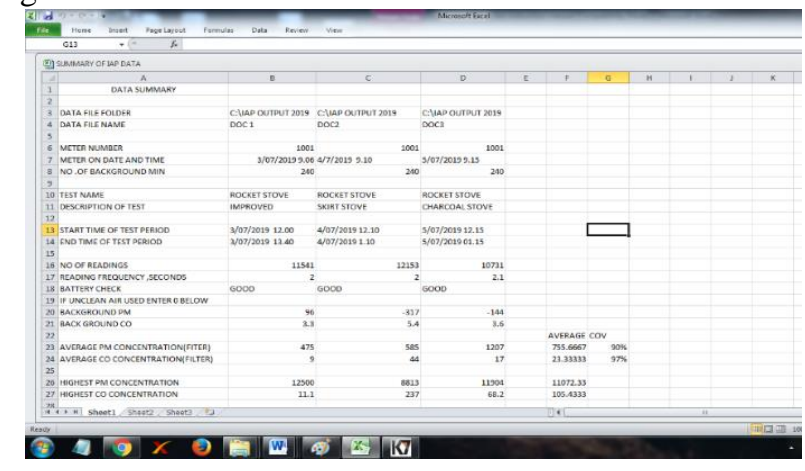

Fig. 20. user data collected from IAP meter 


\section{H) Energy Use}

\section{$\mathbf{E}=\mathbf{C} * \mathbf{V} * \Delta \mathbf{T} / \mathbf{P R}$}

Where E=Energy in $\mathrm{kWh}$

$\mathrm{C}=$ specific heat of water $-0.94 \mathrm{kcal} / \mathrm{kg}^{\circ} \mathrm{c}$

$\mathrm{V}=$ volume of water to heat (litre)

$\Delta \mathrm{T}=\mathrm{T}_{2}-\mathrm{T}_{1}$

$\mathrm{T}_{1}=$ temperature of hot water $^{\circ} \mathrm{c}$

$\mathrm{T}_{2}=$ temperature of cold water ${ }^{\circ} \mathrm{c}$

$\mathrm{PR}=$ performance ratio (it includes loss of heat), default value $=0.9$

$\mathrm{E}=0.94 * 1.839 *(95-25.5) / 0.9$

$\mathrm{E}=133.9 \mathrm{KW}$ for a day

$\mathrm{E}=2.23 \mathrm{KWH}$

$\mathrm{E}=10.5 \mathrm{MJ}$

\section{RESULT AND DISCUSSION}

Average removal efficiencies over a burning cycle. Both filters showed high removal efficiencies for both fine particles, elementary carbon and organic carbon, both fillters are having thehighest efficiency. The Knapsack filter showed a high removal of ultrafine particles as well. No net removal of ultrafine particles over a whole burning cycle (40 min.) was observed in the simulated Carbon with Cellulose Nano fiber filters, But they are filltering the Gases including carbon dioxide $\left(\mathrm{CO}_{2}\right)$, nitrogen dioxide $\left(\mathrm{NO}_{2}\right)$ and carbon monoxide (CO) and Volatile organic compounds. Volatile organic compounds (VOCs) are chemicals found in a wide variety of materials.

When wood is burned, the combustion reaction produces heat and emissions in the form of water, organic vapors, gases, and particulates. The emissions of most concern are carbon monoxide $(\mathrm{CO})$, carbon dioxide $\left(\mathrm{CO}_{2}\right)$, sulfur oxides $\left(\mathrm{SO}_{\mathrm{x}}\right)$, and nitrogen oxides $\left(\mathrm{NO}_{\mathrm{x}}\right)$. Other regulated elements and compounds, such as mercury and hydrochloric acid are measurable in the emissions but at levels much below accepted maximums. The composition and quantity of the emissions is dependent on the combustion temperature. Higher temperatures encourage complete combustion and result in cleaner emissions (up to 1300 celsius). At lower temperatures the emissions can also include volatile organic compounds, relatively high levels of $\mathrm{CO}$ (a product of incomplete combustion), and more particulate concerns. The $\mathrm{NO}_{\mathrm{x}}$ (if kept below 1300 celsius) and $\mathrm{SO}_{\mathrm{x}}$ emissions from burning wood are much lower than those of the fossil fuels coal and petroleum products, and comparable to those of natural gas. Particulate levels in wood emissions are similar to those from burning coal and petroleum and substantially higher than the levels in the emissions from natural gas. Particulate emissions can be controlled to acceptable levels with smoke stack equipment such as scrubbers, bag filters, and electrostatic precipitators. This equipment is however only cost effective on large commercial-sized combustion systems. Particulate emissions from smaller equipment, especially residential-sized units can be a concern. More and more communities and air control districts are placing restrictions on respirable-sized particles $\left(\mathrm{PM}_{2.5}\right.$ or particulate matter smaller than 2.5 microns). Uncontrolled emissions from wood combustion are high in $\mathrm{PM}_{2.5}$. The $\mathrm{CO}_{2}$ in wood combustion emissions is considered "carbon-neutral" because the amount of $\mathrm{CO}_{2}$ emitted during combustion is basically equivalent to the amount of $\mathrm{CO}_{2}$ trees need to grow the same quantity of wood. Hence the combustion of wood does not contribute to the net increase in atmospheric levels of $\mathrm{CO}_{2}$ (a greenhouse gas) as does the combustion of fossil fuels. According to the research [34-36] the important elements present in the emission is in Fig. 21.

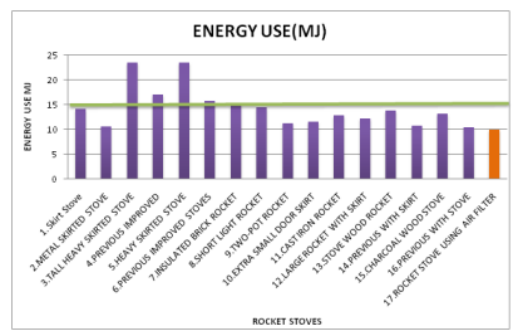

Fig. 21. Energy Use for Stoves to Complete the WBT (Mega Joules). Suggested Fuel (Energy) Use Benchmark: The improved cook stove should use less than $15 \mathrm{MJ}$ of energy to complete the 5-1WBT.

\section{A) Filtration of Exhaust gas}

The Exhaust gas is flow through the exhaust pipe to passing our filters. The following elements are filtered by the following filters in table 1 .

Table 3: Average removal efficiencies over a burning cycle

\begin{tabular}{lllllll}
\hline & $\mathrm{PM}_{10}$ & $\mathrm{PM}_{2.5}$ & $\mathrm{CO}$ & $\mathrm{NO}_{\mathrm{x}}$ & $\mathrm{VOC}$ & $\mathrm{SO}_{\mathrm{x}}$ \\
\hline Knapsack filter & $98 \%$ & $90 \%$ & 0 & 0 & 0 & 0 \\
$\begin{array}{l}\text { Simulated } \\
\text { Carbon with }\end{array}$ & $0.2 \%$ & $10 \%$ & $97 \%$ & $95 \%$ & $90 \%$ & $89 \%$ \\
$\begin{array}{l}\text { Cellulose Nano } \\
\text { fiber filter }\end{array}$ & & & & & & \\
\hline
\end{tabular}

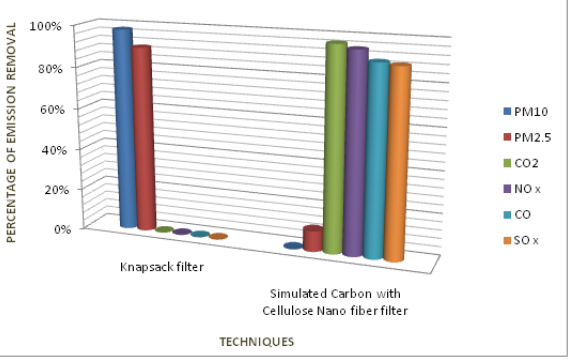

Fig. 22. Removal Quality of filters

The Knapsack filters deals with the particles such as $\mathrm{PM}_{10}$ and $\mathrm{PM}_{2.5}$, whereas it efficiently removes about $98 \%$ and $90 \%$ $\mathrm{PM}_{10}$ and $\mathrm{PM}_{2.5}$ of respectively. Because in our design Simulated Carbon with Cellulose Nano fiber filters are very sensitive to particles, which will reduce the life time of the Simulated Carbon with Cellulose Nano fiber filter. So that we first passing the exhaust gas to knapsack filter shown in fig 23. It is passed through the simulated carbon with cellulose Nano fiber filter. This filter will removes the toxic contents of about $0.2 \%$ of $\mathrm{PM}_{10}, 10 \% \mathrm{PM}_{2.5}, 97 \%$ of $\mathrm{CO}, 95 \%$ of $\mathrm{NO}_{x}, 90 \%$ of VOC and $89 \%$ of $\mathrm{SO}_{\mathrm{x}}$. 


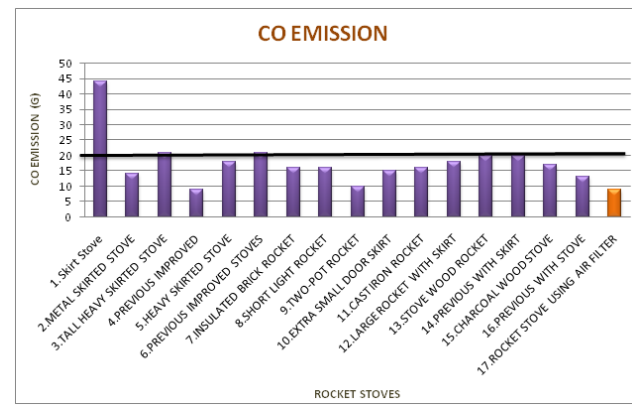

Fig. 23. Carbon Monoxide Emissions to Complete WBT (grams).

Suggested Carbon Monoxide Emission Benchmark: The improved cook stove should emit less than 20 gram so $f$ carbon monoxide to complete the 5-lWBT.

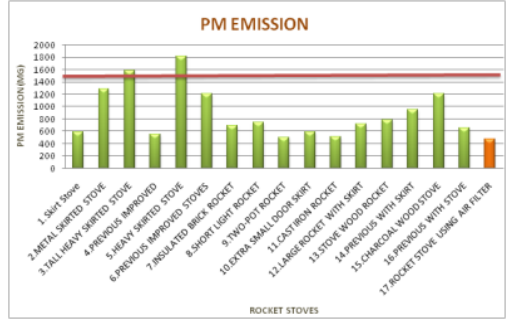

Fig. 24. Particulate Matter Emissions to Complete WBT (milligrams).

Suggested Particulate Matter Emission Benchmark: The improved cook stove should use emit less than 1500 mg of particulate matter to complete the 5-1WBT.

Table 4: value comparison between different rocket stoves

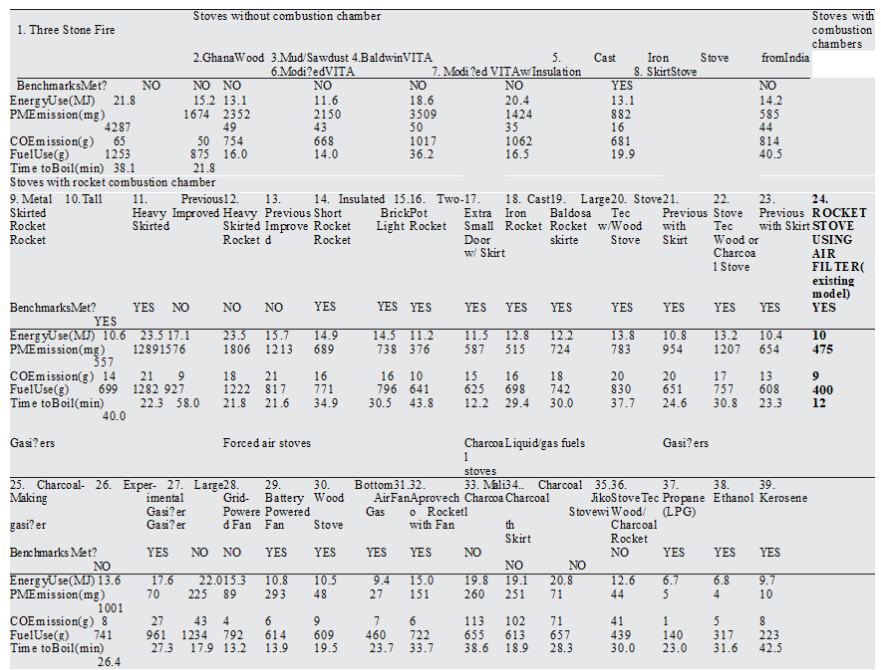

In our proposed method the thermal efficiency is improved due to the waste heat recovery system. When comparing the performance of rocket stoves without heat recovery system with our proposed framework, proposed work exhibits about $70 \%$ thermal efficiency, whereas the prior methodologies achieves only $45 \%$. Thus the efficiency is improved by $30 \%$, which is shown in Fig11. Moreover, the average fuel consumption of our proposed methodology is compared with the prior methodologies such as Traditional Rocket Stove and Catalytic Rocket Stove, which is shown in table 5.

Table 5: Comparison of proposed with existing methodologies in terms of fuel consumption

\begin{tabular}{ll}
\hline Methods & $\begin{array}{l}\text { Average fuel consumption } \\
(\mathbf{g} / \mathbf{L})\end{array}$ \\
\hline Traditional Rocket Stove & 600 \\
Catalytic Rocket Stove & 530 \\
Proposed & 400 \\
\hline
\end{tabular}

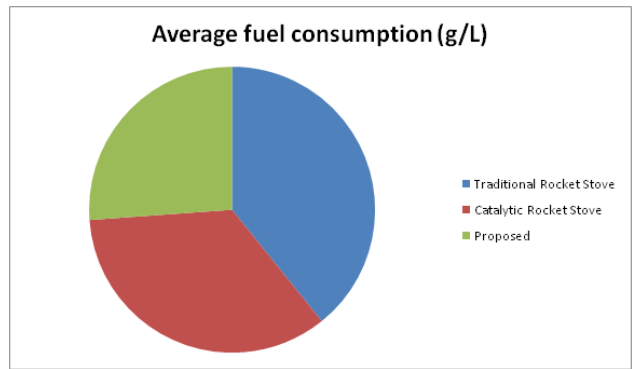

Fig. 25. Comparison of proposed with existing methodologies in terms of fuel consumption

Here the figure 12 shows, the fuel consumption rate is very low for our proposed methodology $400(\mathrm{~g} / \mathrm{L})$, whereas the traditional method consumes $600(\mathrm{~g} / \mathrm{L})$ and the catalytic methodology consumes $530(\mathrm{~g} / \mathrm{L})$. The result shows fuel efficiency rather than the existing. 
Table 6: Comparison of proposed with existing methodologies in terms of PM concentration

\begin{tabular}{ll}
\hline Methods & $\begin{array}{l}\text { Average } \\
\text { concentration }\left(\mu \mathrm{g} / \mathrm{m}^{3}\right)\end{array}$ \\
\hline Traditional Rocket Stove & 5500 \\
Catalytic Rocket Stove & 3800 \\
Proposed & 1750 \\
\hline
\end{tabular}

In case of $\mathrm{PM}$ reduction in table 3, our proposed methodology reduces the average emission to $1750\left(\mu \mathrm{g} / \mathrm{m}^{3}\right)$, while on dealing with the prior methodologies traditional as well as catalytic the average reduction is about 5500 and 3800 $\left(\mathrm{ug} / \mathrm{m}^{3}\right)$ respectively. Thus the system exhibits better results with the reduction of PM emission and is demonstrated through figure 26 .

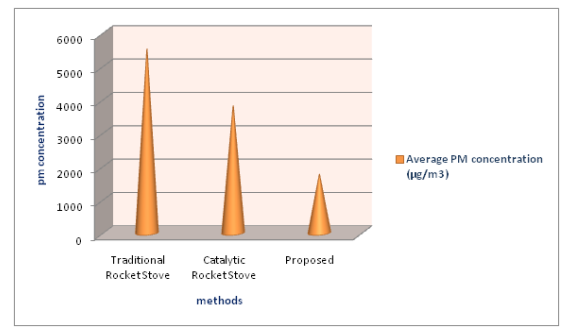

Fig. 26. Comparison of proposed with existing methodologies in terms of PM reduction

Similarly by table 4 , the concentration of $\mathrm{CO}$ is measured using an indoor IAP monitor, which reveals that the proposed methodology releases fewer concentration of $\mathrm{CO}$ (8 ppm). But in terms of existing methodologies, the concentration of $\mathrm{CO}$ is very high, i.e. $35 \mathrm{ppm}$ and $15 \mathrm{ppm}$ respectively and is shown in figure 27.

Table 7: Comparison of proposed with existing methodologies in terms of $\mathrm{CO}$ reduction

\begin{tabular}{cc}
\hline Methods & CO Concentration $(\mathbf{p p m})$ \\
\hline Traditional Rocket Stove & 35 \\
Catalytic Rocket Stove & 15 \\
Proposed & 9 \\
\hline
\end{tabular}

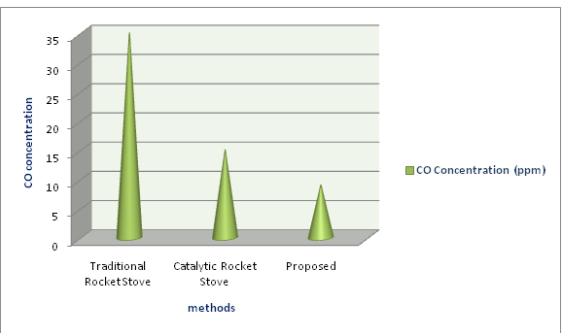

Fig. 25. Comparison of proposed with existing methodologies in terms of $\mathrm{CO}$ reduction

Thus the overall experimental and the comparison results reveals that our proposed methodology achieves better optimized efficiency results in terms of fuel efficiency, thermal efficiencies, reduction in the emission and concentration of $\mathrm{PM}$ as well as $\mathrm{CO}$ than the prior methodologies such as Traditional Rocket Stove and the Catalytic Rocket Stove.

\section{CONCLUSION}

The rocket stove is the mostly used stove in the villages, but the exhaust gases are very danger to humans and animals. So we proposed a methodology that has to discuss in this paper. We used the knapsack filter and Simulated Carbon with Cellulose Nano fiber filters. In our system the Knapsack filters are removed only the particles present in the exhaust and the Simulated Carbon with Cellulose Nano fiber filters are removed the chemical elements present in the exhaust gas. The both filters are highly efficient removal rate. In our research is used to reduce the air pollution and also improve the efficiency of the rocket stove.

\section{REFERENCES}

[1] MacCarty, Nordica, Dean Still, and Damon Ogle, "Fuel use and emissions performance of fifty cooking stoves in the laboratory and related benchmarks of performance," Energy for Sustainable Development, vol. 14, no. 3, pp. 161-171, 2010.

[2] Hanna, Rema, Esther Duflo, and Michael Greenstone, "Up in smoke: the influence of household behavior on the long-run impact of improved cooking stoves," American Economic Journal: Economic Policy, vol. 8, no.1, pp.80-114, 2016.

[3] Proskurina, Svetlana, Martin Junginger, Jussi Heinimö, Beysin Tekinel, and Esa Vakkilainen, "Global biomass trade for energy-Part 2: Production and trade streams of wood pellets, liquid biofuels, and charcoal, industrial round wood and emerging energy biomass," Biofuels, Bio products and Bio refining, 2018.

[4] W.J. Martin, J.W. Hollingsworth and V. Ramanathan, "Household air pollution from cook stoves: impacts on health and climate," In Global Climate Change and Public Health. Humana Press, New York, NY, pp. 237-255, 2014.

[5] A. Price-Allison, A.R. Lea-Langton, E.J.S. Mitchell, B. Gudka, J.M. Jones, P.E. Mason and A. Williams, "Emissions performance of high moisture wood fuels burned in a residential stove," Fuel, vol. 239, pp. 1038-1045, 2019.

[6] A. Williams, J.M. Jones, L. Ma and M. Pourkashanian, "Pollutants from the combustion of solid biomass fuels," Progress in Energy and Combustion Science, vol. 38, no. 2, pp. 113-137, 2012.

[7] Rokni, Emad, Yu Liu, Xiaohan Ren, and A. Yiannis Levendis, "NitrogenBearing Emissions from Burning Corn Straw in a Fixed-Bed Reactor: Effects of Fuel Moisture, Torrefaction, and Air Flow rate," Journal of Energy Resources Technology, vol.141, no.8, pp. 082202, 2019.

[8] L.A. Jozsa, and G.R. Middleton, "A discussion of wood quality attributes and their practical implications,"1994.

[9] Connor, Steven, "Unholy smoke", London Art Workers Guild Evening of Talks Accompanying the Exhibition: Smoke, vol. 13, 2008.

[10] Ostro, D. Bart, J. Michael, Lipsett, K. Jennifer Mann, B. Matthew Wiener, and John Selner, "Indoor air pollution and asthma. Results from a panel study," American journal of respiratory and critical care medicine, vol. 149, no. 6, pp.1400-1406, 1994.

[11] Chafe, Zoë, Michael Brauer, Marie-Eve Héroux, Zbigniew Klimont, Timo Lanki, O. Raimo Salonen and R. Kirk Smith, "Residential heating with wood and coal: health impacts and policy options," in Europe and North America, 2015.

[12] Kshirsagar, P. Milind, and R. A. Vilas Kalamkar, "comprehensive review on biomass cookstoves and a systematic approach for modern cookstove design," Renewable and Sustainable Energy Reviews, vol.30, pp. 580603, 2014.

[13] Änninen, H. Marja-Liisa, "Campylobacter in Poultry Processing," Handbook of Poultry Science and Technology, vol.495, 2010.

[14] Camargo-Valero, Miller, Lies Bamelis, Lies De Clercq, Frank Delvigne, Erik Meers, Evi Michels, Dorian Ramirez-Sosa et al., "Techniques for 
nutrient recovery from household and industrial wastes," Gembloux Agro-Bio Tech, 2015.

[15] Norris, Marc J and Senior Geologist. 3E M M ERING: ANO .

[16] Omer, Abdeen Mustafa, "Focus on low carbon technologies: The positive solution. Renewable and Sustainable Energy Reviews," vol. 12, no. 9, pp. 2331-2357, 2008.

[17] Lauderdale, Chance Venable, "Characterization of a microbial culture capable of removing taste-and odor-causing 2-methylisoborneol from water," PhD diss., University of Florida , 2004.

[18] Meier, Wolfgang, Thomas Pfohl, and PD Dr Cornelia Palivan, Organizing committee of SSD5.

[19] A. Price-Allison, A. R. Lea-Langton, E.J.S. Mitchell, B. Gudka, J. M. Jones, P.E. Mason and A. Williams, "Emissions performance of high moisture wood fuels burned in a residential stove," Fuel, vol. 239, no.1038-1045, 2019.

[20] Snider, Graydon, Ellison Carter, Sierra Clark, Xudong Yang, Majid Ezzati, J. James Schauer, Christine Wiedinmyer, and Jill Baumgartner, "Impacts of stove use patterns and outdoor air quality on household air pollution and cardiovascular mortality in southwestern China," Environment international, vol. 117, pp. 116-124, 2018.

[21] de la Sota, Candela, Julio Lumbreras, Noemí Pérez, Marina Ealo, Moustapha Kane, Issakha Youm, and Mar Viana, "Indoor air pollution from biomass cook stoves in rural Senegal," Energy for Sustainable Development, vol. 43, pp. 224-234, 2018.

[22] Press-Kristensen, Kåre, Lotte Laurvig, Patrick Huth, Axel Friedrich, and Teis Nørgaard Mikkelsen, "Flue gas cleaning for stoves \& boilers," In 22nd ETH-Conference on Combustion Generated Nanoparticles, 2018.

[23] Kantová, Nikola, Alexander Čaja, Michal Holubčík, and Jozef Jandačka, "Flow modelling of particulate matter by using baffles placed in the flue tract of wood stove," In MATEC Web of Conferences, vol. 168, 2018.

[24] T. Makonese, and C. Bradnum, "Public participation in technological innovation: The case of the Tshulu stove development programme," Journal of Energy in Southern Africa, vol. 28, no. 1, pp. $13-24,2017$.

[25] A. D. Paulsen, T. A. Kunsa, A. L. Carpenter, T.J. Amundsen, N. R. Schwartz, J. Harrington, J. Reed, B. Alcorn, J. Gattoni, and P. E. Yelvington, "Gaseous and particulate emissions from a chimneyless biomass cookstove equipped with a potassium catalyst," Applied Energy, vol.235, pp.369-378, 2019.

[26] Fuel Efficient Stoves for Darfur Camps of Internally Displaced PersonsReport of Field Trip to North and South Darfur, 2005.

[27] A. Williams, J.M. Jones, L. Ma and M. Pourkashanian, "Pollutants from the combustion of solid biomass fuels," Progress in Energy and Combustion Science, vol.38, no.2, pp.113-137, 2012.

[28] Fernando, Sujan, Lorraine Shaw, Don Shaw, Michael Gallea, Lori Vanden Enden, Ron House, K. Dave Verma, Philip Britz-McKibbin, and E. Brian McCarry, "Evaluation of firefighter exposure to wood smoke during training exercises at burn houses," Environmental science \& technology, vol.50, no.3, pp.1536-1543, 2016.

[29] Huboyo, S. Haryono, Susumu Tohno, and Renqiu Cao, "Indoor PM2. 5 characteristics and $\mathrm{CO}$ concentration related to water-based and oilbased cooking emissions using a gas stove," Aerosol and Air Quality Research, vol.11, no.4, pp. 401-411, 2011.

[30] Agarwal, Avinash Kumar, Akhilendra Pratap Singh, and Rakesh Kumar Maurya, "Evolution, challenges and path forward for low temperature combustion engines," Progress in Energy and Combustion Science, vol. 61, no. 1-56, 2017.

[31] N.C. Gallego, and J. W. Klett, "Carbon foams for thermal management," Carbon, vol. 41, no.7, pp. 1461-1466, 2003.

[32] Barrett, E. Michael, D. Robert Zuber, R. Edmond Collins, F. Joseph Malina, J. Randall Charbeneau and H. George Ward, "A review and evaluation of literature pertaining to the quantity and control of pollution from highway runoff and construction," 1995.

[33] Zhan, Minshu, Guogang Sun, Shen Yan, Jiaqing Chen, and Minghao You, "Filtration Performance of Coal Pyrolysis Flying Char Particles in a Granular Bed Filter," Energy \& fuels, vol. 32, no.2, pp. 1070-1079, 2018

[34] Dasch, Jean Muhlbaier, "Particulate and gaseous emissions from woodburning fireplaces," Environmental Science \& Technology, vol.16, no.10, pp. 639-645, 1982.

[35] S. Weimer, M. R. Alfarra, D. Schreiber, M. Mohr, S. H. Andre Prévôt, and U. Baltensperger, "Organic aerosol mass spectral signatures from wood- burning emissions: Influence of burning conditions and wood type," Journal of Geophysical Research: Atmospheres, vol.113, no. (D10), 2008.

[36] M. Negri, M. Fellin, V. Carè, and A.R. Proto, "Integrated pyrogasification process of heterogeneous mediterranean wood species," Contemporary Engineering Sciences, vol. 9, no.23, pp. 1113-1123, 2016.

[37] Drave, Arvindkumar, and K. P. Mishra. "Development of energy efficient cooking systems for rural masses. International Journal of Management," Information Technology and Engineering, vol. 4, no. 2, pp. 37-48, 2016.

[38] Khan, Sabrina, Tania Hossain, and Md Mominur Rahman, "Development of Portable Rocket Stove and Performance Evaluation," 2016.

[39] MacCarty, Nordica, Dean Still, Damon Ogle, and Thomas Drouin, "Assessing cook stove performance: field and lab studies of three rocket stoves comparing the open fire and traditional stoves," in Tamil Nadu, India on measures of time to cook, fuel use, total emissions, and indoor air pollution. Aprovecho Research Center, 2008.

[40] Thompson, M. Lisa., Nigel Bruce, Brenda Eskenazi, Anaite Diaz, Daniel Pope, and R. Kirk Smith, "Impact of reduced maternal exposures to wood smoke from an introduced chimney stove on newborn birth weight in rural Guatemala," Environmental health perspectives, vol. 119, no.10, pp.1489-1494, 2011.

\section{Creative Commons Attribution License 4.0 (Attribution 4.0 International, CC BY 4.0)}

This article is published under the terms of the Creative Commons Attribution License 4.0 https://creativecommons.org/licenses/by/4.0/deed.en_US 